\title{
Dynamic Economic Dispatch pada Sistem dengan Wind Turbine dan Media Penyimpanan Energi Mempertimbangkan Energy Cycle Limit
}

\author{
Galih Budi Virgiansyah, Rony Seto Wibowo, dan Dedet Candra Riawan \\ Departemen Teknik Elektro, Fakultas Teknologi Elektro, Institut Teknologi Sepuluh Nopember (ITS) \\ e-mail: galihbudiv.7@gmail.com
}

\begin{abstract}
Abstrak-Kebutuhan daya listrik yang semakin meningkat seiring berkembangnya jaman berbanding terbalik dengan ketersediaan sumber energi yang tidak dapat diperbaharui seperti minyak dan batu bara. Adanya inovasi dengan pengoptimalan energi terbarukan yang mulai digunakan menjadi solusi dari permintaan kebutuhan daya listrik yang semakin tinggi. Dengan cakupan wilayah yang semakin luas, juga diperlukan pembangkit tenaga listrik yang mampu untuk memenuhi permintaan tersebut. Berbanding lurus dengan permintaan daya listrik, suatu sistem diharapkan mampu menyuplai beban dengan optimal dan ekonomis. Dengan penggunaan Dynamic Economic Dispatch (DED), suatu pembangkit dapat dioptimalkan agar diperoleh biaya pembangkitan yang minimal terhadap permintaan daya listrik. Pada penelitian ini, digunakan perhitungan menggunakan file Matpower yang ada pada MATLAB dengan metode quadratic programming. Batasan yang dimasukkan adalah terkait keseimbangan daya pembangkit, ramp rate ataupun charging discharging yang ada pada media penyimpanan energi (baterai). Penelitian ini diharapkan mampu diperoleh pengaruh penambahan pembangkit renewable terhadap total biaya pembangkitan dan mengetahui lifetime dari baterai dari sistem tenaga listrik.
\end{abstract}

Kata Kunci-DED, Batasan Operasi, Quadratic Programming, Lifetime baterai.

\section{PENDAHULUAN}

$\mathrm{K}$ ONSUMSI energi listrik yang semakin meningkat, membutuhkan permintaan energi yang juga semakin besar . Untuk mengatasi permasalahan yang semakin menipisnya energi berbahan bakar seperti fosil, pengembangan energi terbarukan adalah solusinya. Sudah bukan hal umum ketika energi terbarukan sedang diperbincangkan terkait pengoptimalannya sebagai solusi pengganti energi yang tak dapat diperbaharui. Salah satunya dengan wind turbine dan media penyimpanan energi untuk memenuhi konsumsi kebutuhan listrik sehari-hari. Berbagai upaya dilakukan dalam bidang teknologi agar mampu memaksimalkan energi terbarukan ini. Dengan adanya wind turbine dan media penyimpanan energi ini, diharapkan mampu menjadi pembangkit yang dapat menopang kinerja pembangkit thermal dalam memenuhi permintaan daya listrik bagi konsumen. Selain itu dengan adanya pembangkit renewable ini, diharapkan mampu meminimalisir total biaya pembangkitan agar lebih ekonomis dan terjangkau.

\section{PEMODELAN SISTEM}

\section{A. Wind Turbine}

Wind turbine adalah suatu pembangkit listrik terbarukan yang memanfaatkan energi angin dan dirubah menjadi energi listrik. Desain wind turbine terdiri dari dua hal penting yang harus diperhitungkan yaitu ketersediaan angin dan kurva daya dari wind turbine itu sendiri. Keluaran daya dari wind turbine merupakan fungsi dari kecepatan angin. Memodelkan performansi dari wind turbine, kurva daya harus diperoleh. Berikut adalah kurva daya dari keluaran wind turbine tipe Siemens SWT-2.3-82 - Manufacturers and turbines dengan rating $2.3 \mathrm{MW}$ :

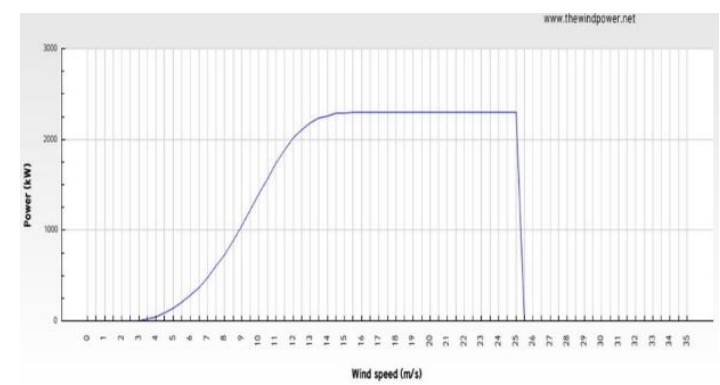

Gambar 1. Kurva Daya Wind Turbine Siemens SWT-2.3-82

Dari model kurva daya tersebut dapat diperoleh persamaan sebagai berikut :

$$
\begin{array}{lc}
P_{W T}=0, & \boldsymbol{V}_{a c}<\boldsymbol{V}_{\boldsymbol{c} i} \\
P_{W T}=a V^{3}{ }_{a c}+b V^{2}{ }_{a c}+c V_{a c}+d, & \boldsymbol{V}_{c \boldsymbol{c}} \leq \boldsymbol{V}_{\boldsymbol{a c}} \leq \boldsymbol{V}_{\boldsymbol{r}} \\
P_{W T, r}=V_{r}, & \boldsymbol{V}_{\boldsymbol{r}} \leq \boldsymbol{V}_{\boldsymbol{a c}} \text { dan } \boldsymbol{V}_{\boldsymbol{c} \boldsymbol{c}}>\boldsymbol{V}_{\boldsymbol{a c}}
\end{array}
$$

Dimana, $P_{W T}$ adalah daya keluaran dari wind turbine dalam (MW), $P_{\text {co }}$ adalah daya saat cut-out dalam (MW), $V_{r}$ adalah rating kecepatan angin dalam $(\mathrm{m} / \mathrm{s}), V_{a c}$ adalah kecepatan angin aktual dalam $(\mathrm{m} / \mathrm{s}), V_{c i}$ adalah kecepatan $c u t$-in dalam $(\mathrm{m} / \mathrm{s})$ dan $V_{c o}$ adalah kecepatan cut-out dalam $(\mathrm{m} / \mathrm{s})$.

\section{B. Media Penyimpanan Energi}

Pada sistem kelistrikan ini yang disambungkan dengan media penyimpanan energi (baterai), baterai mampu menjadi pensuplai daya maupun beban, tergantung dari besar pembangkitan pembangkit thermal dan renewable yaitu wind turbine. Baterai memiliki kemampuan untuk menyimpan kelebihan daya dari pembangkitan renewable dan memberikan pasokan daya ketika sistem mengalami kekurangan daya.

Strategi yang digunakan untuk melakukan penghematan adalah dengan mengatur penggunaan baterai, hal tersebut juga akan berimbas pada kerja sistem kelistrikan secara keseluruhan. Pada setiap waktu state of charge (SOC) dari baterai harus memenuhi persyaratan yang ditunjukkan oleh persamaan berikut:

$$
\begin{aligned}
& S O C \min \leq S O C \leq S O C \max \\
& -P \text { cha_max } \leq P \text { batt } \leq P \text { discha_max }
\end{aligned}
$$


Besarnya nilai charging atau discharging pada saat $(t)$ tertentu diperoleh dengan perhitungan matematis sebagai berikut :

$$
E_{\text {min }} \leq E(t)-\sum_{s=0}^{k} P_{\text {batt }} \Delta t \leq E_{\text {max }}
$$

Dimana, $E_{\min }$ adalah energi minimum pada baterai (MWh) dan $E_{\max }$ adalah energi maksimum pada baterai (MWh). Dan pada penelitian ini menggunakan baterai dengan tipe Li-Ion Battery $12.8 \mathrm{~V}, 300$ Ah yang akan dihubungkan pada sistem dengan wind turbine.

\section{Energy Cycle Limit}

Pada penelitian ini yang dimaksud dengan energy cycle limit adalah batas energi yang digunakan pada baterai dalam proses charging discharging untuk dapat mengetahui perputaran energi yang ada pada baterai atau batas energi yang dilalui pada baterai dalam seumur hidup (Qlifetime). Seperti persamaan yang ada di bawah ini :

ESS, energy cycle limit :

$$
\sum E_{\text {batt }} \leq Q_{\text {lifetime }}
$$

Dimana, $E_{\text {batt }}$ adalah energi pada baterai pada periode waktu (h) (MWh) $Q_{\text {lifetime }}$ adalah energi yang dilalui pada baterai dalam seumur hidup (MWh).

Total energi yang ada pada baterai saat proses charging discharging akan dikonversikan dalam bentuk cycle baterai, yang nantinya cycle baterai ini akan digunakan untuk menghitung lifetime dari baterai tersebut. Batas minimum dan maksimum dari SOC pada baterai juga menjadi faktor utama yang mempengaruhi lama lifetime baterai selain dilihat dari kapasitas dari baterai tersebut. Berikut adalah persamaan dalam menentukan cycle dari baterai :

$$
\operatorname{cycle}_{(\text {day })}=\frac{\sum_{i=0}^{n} P_{c h}, P_{d i s}}{\text { Cbatt }}
$$

Dimana, $C_{\text {batt }}$ adalah kapasitas baterai (MWh), $P_{c h}$ adalah daya yang masuk pada baterai pada periode waktu $(h)(\mathrm{MW})$, dan $P_{\text {dis }}$ adalah daya yang keluar pada baterai pada periode waktu $(h)(\mathrm{MW})$.

\section{Quadratic Programming Pada Dynamic Economic Dispatch}

Quadratic programming merupakan salah satu fungsi pada MATLAB untuk menyelesaikan fungsi kuadrat. Dalam penelitian ini untuk melakukan penyelesaian pada dynamic economic dispatch yaitu dengan menggunakan Matpower.

\section{1) Input Argumen}

Terdapat fungsi qps_matpower yang ada pada Matpower untuk pengembangan dari quadratic programming itu sendiri. Input argumen tersebut adalah sebagai berikut:

- $\mathrm{H}=$ Matriks simetris yang menyatakan bentuk kuadratik dari persamaan $1 / 2 * x * H^{*} \mathrm{x}+\mathrm{c}$ 'x

- $\mathrm{c}=$ Merupakan vektor yang menyatakan bentuk linier dari persamaan $1 / 2 * x * H^{*} \mathrm{x}+\mathrm{c}{ }^{\prime} \mathrm{x}$

- $\mathrm{A}=$ Matriks yang menyatakan koefisien linier dari equality dan inequality constraint $A^{*} x \leq b$

- $l b=$ Vektor yang menyatakan batas bawah dari permasalahan $\mathrm{lb} \leq \mathrm{x} \leq \mathrm{ub}$

- $u b=$ Vektor yang menyatakan batas atas dari permasalahan $\mathrm{lb} \leq \mathrm{x} \leq \mathrm{ub}$

- $x_{0}=$ Optional vektor yang menyatakan initial point dari algoritma quadprog

\section{E. Sintaksis Quadratic Programming Pada Matpower}

Perintah yang dapat digunakan untuk memanggil program dengan input argument dalam qps_matpower adalah sebagai berikut:

- $\quad \mathrm{x}=\mathrm{qps} \_$matpower $(\mathrm{H}, \mathrm{c}, \mathrm{A}, \mathrm{l}, \mathrm{u})$

Meminimalkan vektor $\mathrm{x}$ terhadap inequality dan equality constraint $1 \leq \mathrm{A}^{*} \mathrm{x} \leq \mathrm{u}, \mathrm{H}$ dan $\mathrm{c}$ merupakan fungsi objektif quadratic programming.

- $\quad \mathrm{x}=$ qps_matpower (H, c, A, 1, u, xmin, xmax)

Meminimalkan vektor $\mathrm{x}$ terhadap inequality dan equality constraint $1 \leq \mathrm{A}^{*} \mathrm{x} \leq \mathrm{u}$ dan terdapat batasan nilai $\mathrm{x}$ maksimal dan $\mathrm{x}$ minimal. $\mathrm{H}$ dan $\mathrm{c}$ merupakan fungsi objektif quadratic programming.

- $\quad \mathrm{x}=\mathrm{qps}$ _matpower $(\mathrm{H}, \mathrm{c}, \mathrm{A}, \mathrm{1}, \mathrm{u}, \mathrm{xmin}, \mathrm{xmax}, \mathrm{x} 0)$

Menyelesaikan permasalahan quadratic programming dengan inisialisasi nilai awal $\mathrm{x} 0$ untuk mempercepat proses pencarian.

\section{F. Inisiasi Permasalahan Dynamic Economic Dispatch}

Nilai objective function sebagai fungsi kuadratik yang berasal dari koefisien biaya tiap pembangkit akan diproses oleh quadratic programming dengan persamaan sebagai berikut :

$$
\text { Min } O F=\sum_{t=1}^{T}\left(\sum_{h=1}^{n}\left(a_{h t} P_{h t}^{2}+b_{h t} P_{h t}+c_{h t}\right)\right) \$ / h
$$

Dimana , $a, b$, dan $c$ adalah koefisien biaya generator dan $P_{h t}$ daya yang dibangkitkan pembangkit $h$ pada periode waktu (t) (MW).

\section{1) Equality Constraint}

Active Power Balance

$$
\begin{gathered}
P_{L i}^{t}-P_{G i}^{t}+P_{I N i}^{t}=0 \\
P_{I N}^{t}=\sum \frac{1}{x_{i j}}\left[\delta_{i}-\delta_{j}\right]
\end{gathered}
$$

Dimana, $P_{I N}$ adalah daya yang mengalir pada saluran dari bus $i$ ke bus $j, P_{L i}$ adalah daya pada load bus i, $P_{G i}$ adalah daya pembangkitan generator pada bus $i, \delta$ adalah sudut tegangan, dan $x$ adalah nilai reaktansi saluran.

2) Inequality Constraint

$$
\begin{aligned}
& \text { Ramp Rate } \\
& -\delta_{i} \leq P_{G i}^{t+1}-P_{G i}^{t} \leq \delta_{i} \\
& \text { Daya Pembangkitan } \\
& P_{\text {Gi min }} \leq P_{G i} \leq P_{\text {Gi max }} \\
& \text { Charging Discharging } \\
& \text { Emin } \leq E(t)+\sum_{s=0}^{k} \text { Pbatt } \Delta t \leq \text { Emax }
\end{aligned}
$$

\section{STUDI KASUS}

Beberapa kasus ini akan dilakukan dengan menggunakan sistem IEEE 30 bus dengan metode penyelesaiannya berupa quadratic programming pada dynamic economic dispatch. Berikut single line diagram dari sistem IEEE 30 bus pada gambar 2: 


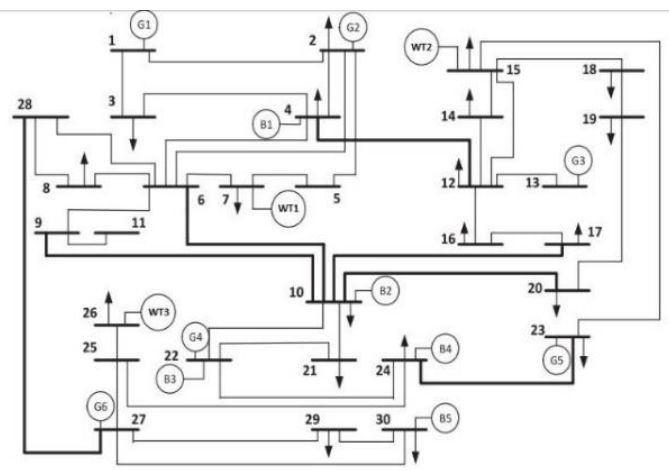

Gambar 2. Single Line Diagram IEEE 30 Bus.

Total beban yang diperoleh untuk penelitian ini adalah selama 24 jam dan terdapat dua profil beban yang dugunakan yaitu pada weekdays dan weekend. Dua perbedaan profil beban ini hanya akan mengetahui perbedaan permintaan beban pada hari biasa dan akhir pekan. Dan berikut adalah kurva beban yang digunakan pada penelitian ini pada gambar 3 dan total beban harian pada tabel 1

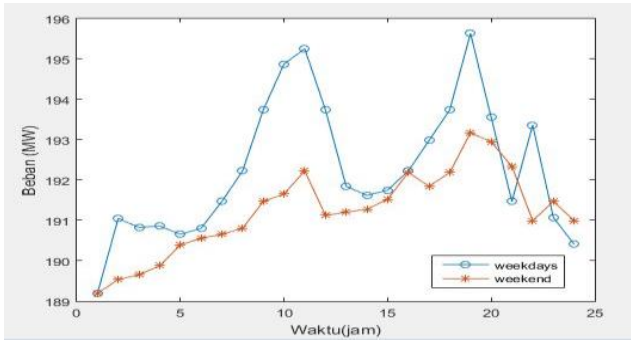

Gambar 3. Kurva Pembebanan Weekdays dan Weekend

Tabel 1.

Total Pembebanan Weekdays dan Weekend

\begin{tabular}{ccc}
\hline \hline JAM & $\begin{array}{c}\text { Total Beban } \\
(\mathrm{MW}) \text { Weekdays }\end{array}$ & $\begin{array}{c}\text { Total Beban } \\
(\mathrm{MW}) \text { Weekend }\end{array}$ \\
\hline TOTAL & 4606.9066 & 4589.3847 \\
\hline \hline
\end{tabular}

Dari data pembebanan yang diperoleh dari tabel diatas, terdapat adanya perbedaan permintaan beban antara weekdays dan weekend. Untuk permintaan beban pada weekdays lebih besar dikarenakan daya tenaga listrik yang digunakan lebih tinggi akibat aktivitas yang sering dilakukan seperti beban yang ada pada industri-industri yang beraktivitas pada harihari aktif (weekdays).

\section{A. Studi Kasus 1}

Studi kasus 1 akan merepresentasikan keadaan sistem IEEE 30 bus yang tidak terhubung dengan wind turbine dan baterai dalam periode waktu 24 jam. Terdapat 6 generator yang ditinjau pada studi kasus ini dan akan diperoleh total biaya pembangkitan pada masing-masing periode waktu.

Diperoleh total biaya pembangkitan adalah sebesar:

\section{Total biaya $=\$ 13,845.44$ weekdays \\ Total biaya $=\$ 13,749.28$ weekend}

Dari hasil simulasi diperoleh perbedaan total biaya pada weekdays dan weekend dari pembangkitan 6 generator yang ada pada sistem tersebut. Hal itu dikarenakan permintaan beban pada weekdays dan weekend yang berbeda. Permintaan beban berbanding lurus dengan biaya pembangkitan dari tiap generator ditinjau dari biaya bahan bakar masing-masing generatornya.

\section{B. Studi Kasus 2}

Pada Studi kasus ini akan ada penambahan wind turbine yang terhubung pada sistem sebanyak 3 buah dengan asumsi kecepatan angin yang ada berubah-ubah setiap periode waktunya (24 jam). Data yang dimasukkan menggunakan IEEE 30 bus dengan inputan kecepatan angin ditunjukkan pada gambar 4 :

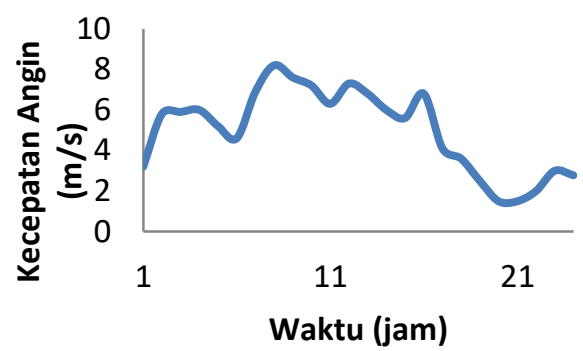

Gambar 4. Grafik Kecepatan Angin

Dan diperoleh total biaya pembangkita pada masingmasing periode waktu ketika terdapat penambahan wind turbine adalah sebesar :

\section{Total Biaya $=\$ 12,898.17$ weekdays \\ Total biaya $=\$ 12,808.13$ weekend}

Kecepatan angin yang berubah-ubah terhadap periode waktu mempengaruhi daya pembangkitan yang ada pada wind turbine itu sendiri. Didapatkan total biaya pembangkitan yang lebih murah pada studi kasus 2 dibandingkan studi kasus 1 baik itu pada weekdays dan weekend. Penambahan wind turbine di dalam sistem bertujuan untuk meminimalisir total biaya pembangkitan yang ada pada pembangkit thermal. Dikarenakan pada wind turbine sendiri tidak adanya cost function ataupun biaya bahan bakar yang dikeluarkan, dengan ketentuan batasan biaya operasi dan maintenance pembangkit renewable diabaikan.

\section{Studi Kasus 3}

Pada studi kasus ini akan ada penambahan media penyimpanan energi (baterai) pada sistem. Melanjutkan yang ada pada studi kasus 2 untuk data masukan pada pembahasan kasus ini, pada studi kasus ini akan mengetahui pengaruh penambahan baterai pada sistem. Dalam penelitian ini akan dibahas mengenai charging discharging baterai yang akan mempengaruhi lifetime dari baterai sendiri. Terdapat total 5 baterai dengan kapasitas masing-masing sebesar 38.4 MWh yang akan dihubungkan pada sistem. bab studi kasus 3 ini.

Pada studi kasus 3 ini akan mengetahui kemampuan baterai saat charging discharging. Akan diperoleh total charging dan discharging baterai pada periode waktu 24 jam yang akan menentukan berapa cycle baterai selama periode waktu tersebut. Sebagai masukan untuk studi kasus 3 ini adalah data baterai yang meliputi kapasitas baterai, $S O C_{\max }$, $S O C_{\min }$, dan $P_{\max }$ baterai pada tabel 2 dan charging discharging pada baterai ditunjukkan pada gambar $5 \& 6$ :

Tabel 2.

Data Masukan Baterai

\begin{tabular}{lcc}
\hline & Case & \\
SOCmax & $100 \%$ & Data Baterai (MWh) \\
SOCmin & $20 \%$ & \\
SOCawal & $20 \%$ & \\
Emax & $3840 \mathrm{Wh}$ & 38.4 \\
Emin & $768 \mathrm{Wh}$ & 7.68 \\
\hline \hline
\end{tabular}




\begin{tabular}{lll}
\hline \hline Eo & $768 \mathrm{Wh}$ & 7.68 \\
Pchmax & & 7.68 \\
Pdismax & & 3.84 \\
Kapasitas & & \\
baterai & 38.4 & \\
\hline
\end{tabular}

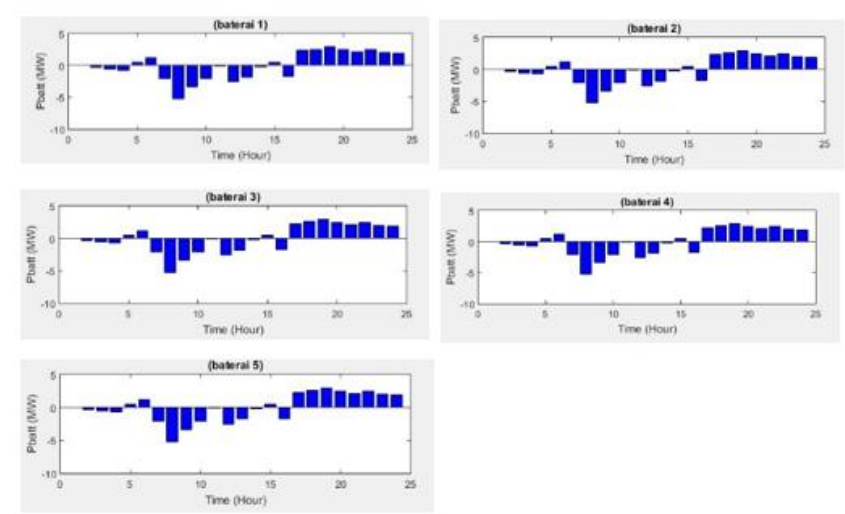

Gambar 5. Charging Discharging Baterai Saat Weekdays

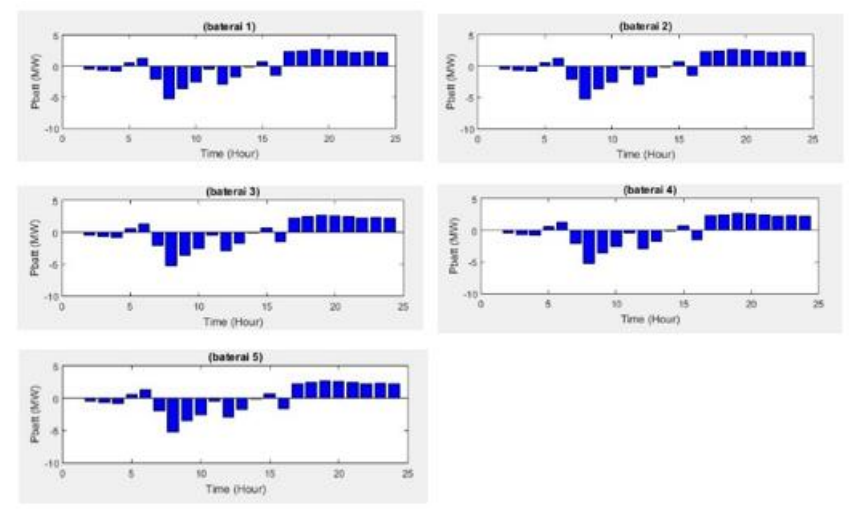

Gambar 6. Charging Discharging Baterai Saat Weekend

Diperoleh total biaya pembangkitan dari hasil simulasi sebesar:

\section{Total Biaya $=\$ 12,892.81$ weekdays}

Total Biaya $=\$ 12,799.19$ weekend

Dari hasil simulasi studi kasus 3 yang terdapat penambahan media penyimpanan energi pada sistem, didapatkan perubahan biaya pembangkitan yang tidak terlalu signifikan dengan studi kasus 2. Hal ini dikarenakan tidak adanya biaya bahan bakar yang ada pada baterai sehingga biaya pembangkitan hanya ada pada pembangkit thermal yang ada pada sistem. Namun, dapat dilihat proses charging discharging baterai pada saat weekdays dan weekend mengalami perbedaan.

\section{HASIL ANALISA DAN KESIMPULAN}

Dari perhitungan dengan tiga studi kasus yang berbeda, diperoleh total biaya pembangkitan yang berbeda-beda antara studi kasus 1, 2 dan 3. Total biaya dari hasil simulasi menggunakan Matpower pada MATLAB akan ditunjukkan pada tabel 3:

Tabel 3.

Cost Function Hasil Simulasi

\begin{tabular}{|c|c|c|c|c|c|c|}
\hline \multirow{3}{*}{ Cost $(\$)$} & \multicolumn{6}{|c|}{ Sistem IEEE 30 bus } \\
\hline & $\begin{array}{l}\text { Wind } \\
\text { Tubine }\end{array}$ & Baterai & $\begin{array}{l}\text { Wind } \\
\text { turbine }\end{array}$ & Baterai & $\begin{array}{c}\text { Wind } \\
\text { turbine }\end{array}$ & Baterai \\
\hline & No & No & Yes & No & Yes & Yes \\
\hline Weekdays & $\$ 13$, & 45.44 & $\$ 12$, & 8.17 & $\$ 12$, & 2.81 \\
\hline
\end{tabular}

Weekend

$\$ 13,749.28$

$\$ 12,808.13$

$\$ 12,799.19$

Dengan penambahan wind turbine pada studi kasus 2 dan pada studi kasus 3 penambahan wind turbine dan baterai, jelas diperoleh cost function hasil simulasi dari periode waktu weekdays dan weekend menjadi lebih murah. Hal ini dikarenakan tidak adanya biaya bahan bakar dari wind turbine dan baterai ataupun biaya maintenance dari kedua pembangkit tersebut. Berbeda dengan pembangkit thermal berjumlah 6 buah yang memiliki karakteristik yang berbeda-beda dilihat dari biaya bahan bakar dari masing-masing pembangkit.

Tabel 4.

Data Hasil Simulasi Baterai

\begin{tabular}{ccc}
\hline & \multicolumn{3}{c}{ Case } \\
& Weekend & Weekdays \\
\hline Total charging/batt & 20.79 & 21.49 \\
Total discharging/batt & 20.801 & 21.503 \\
Cycle/week \\
Years
\end{tabular}

Hasil simulasi diatas diperoleh bahwa pada studi kasus yang ada pada baterai terkait kapasitas baterai, terdapat perbedaan cycle baterai di setiap simulasi pada weekdays dan weekend. Hal tersebut dikarenakan pengaruh dari total charging discharging baterai terhadap permintaan beban yang ada. Dan hal tersebut mempengaruhi state of charge (SOC) pada baterai untuk setiap periode waktunya. Dan diperoleh hasil akumulasi selama per pekan untuk total cycle baterai seumur hidup (sekali pemakaian baterai) dari tabel 4. adalah dalam kurun waktu sekitar 7.43 tahun (lifetime baterai).

Berdasarkan hasil simulasi dari penelitian ini dengan menggunakan quadratic programming pada analisis dynamic economic dispatch dalam suatu sistem IEEE 30 bus dengan variasi penambahan pembangkit renewable (wind turbine) dan media penyimpanan energi (baterai) diperoleh beberapa kesimpulan adalah sebagai berikut:

1. Dengan quadratic programming dapat diperoleh hasil yang paling minimal pada pembangkitan dengan menetukan pembebanan pada tiap pembangkit.

2. Penambahan adanya wind turbine dan baterai dapat memberikan pengaruh yang cukup signifikan terhadap perhitungan total biaya pembangkitan

3. Dapat menghemat sekitar $7 \%$ dari total biaya pembangkitan ketika sistem ditambahkan wind turbine dan baterai, baik itu saat weekdays ataupun weekend

4. Dengan penggunaan baterai dengan total pembebanan yang berbeda pada weekdays dan weekend akan didapatkan bahwa total pembebanan saat weekdays akan membuat cycle baterai lebih kecil dibandingkan total pembebanan saat weekend. Hal ini dikarenakan total pembebanan berbanding lurus dengan cycle yang ada pada baterai (kapasitas baterai).

\section{DAFTAR PUSTAKA}

[1] E. S. Matee and G. Radman, "Determination of optimum economic power commitment by wind farms equipped with energy storage system," in SOUTHEASTCON 2014, IEEE, 2014, pp. 1-6.

[2] W. Liu, Z. Luan, Y. Yang, R. Gan, and H. Zhao, "The application of the improved Particle Swarm Optimization on dynamic economic dispatch of power system with wind farms," in TENCON 2015-2015 IEEE Region 10 Conference, 2015, pp. 1-6. 
[3] N. Yan, Z. X. Xing, W. Li, and B. Zhang, "Economic Dispatch Application of Power System With Energy Storage Systems," IEEE Trans. Appl. Supercond., vol. 26, no. 7, pp. 1-5, Oct. 2016.

[4] L. Xiaoping, D. Ming, H. Jianghong, H. Pingping, and P. Yali, "Dynamic economic dispatch for microgrids including battery energy storage," in Power Electronics for Distributed Generation Systems (PEDG), 2010 2nd IEEE International Symposium on, 2010, pp. 914917.

[5] Y. Zhang, N. Rahbari-Asr, J. Duan, and M.-Y. Chow, "Day-Ahead Smart Grid Cooperative Distributed Energy Scheduling With Renewable and Storage Integration," IEEE Trans. Sustain. Energy, vol. 7, no. 4, pp. 1739-1748, Oct. 2016.

[6] N. Yan, Z. X. Xing, W. Li, and B. Zhang, "Economic dispatch analysis of wind power integration into power system with energy storage systems," in Applied Superconductivity and Electromagnetic Devices (ASEMD), 2015 IEEE International Conference on, 2015, pp. 141-142.

[7] C.-L. Nguyen, T.-W. Chun, and H.-H. Lee, "Determination of the optimal battery capacity based on a life time cost function in wind farm," in Energy Conversion Congress and Exposition (ECCE), 2013 IEEE, 2013, pp. 51-58. 